\section{ECONOMICS}

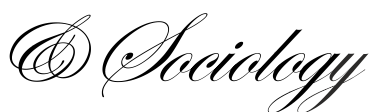

Bhukuth, A., Bazin, D., Khraief, N., \& Terrany, B. (2019). The economics of farmers' suicide in developing countries. Economics and Sociology, 12(2), 143-154. doi:10.14254/2071-789X.2019/12-1/8

\title{
THE ECONOMICS OF FARMERS' SUICIDE IN DEVELOPING COUNTRIES
}

\author{
Augendra Bhukuth, \\ ITSMI School of Management \\ Paris, France \\ E-mail: angendra@gmail.com \\ Damien Bazin, \\ Côte d'Azur Université \\ CNRS, GREDEG \\ Nice, France \\ E-mail:damien.barin@unice.fr
}

\author{
Naceur Khraief, \\ Tunis Business School \\ Université de Tunis \\ Tunis, Tunisia \\ E-mail:naceur.kbraief@tunis- \\ business-school.tn
}

\author{
Bernard Terrany, \\ Ipag Business School \\ Paris, France \\ E-mail:b.terrany@ipag.fr \\ Received: August, 2018 \\ 1st Revision: December, 2018 \\ Accepted: January, 2019
}

DOI: $10.14254 / 2071-$

789X.2019/12-1/8

JEL Classification:D62, D63, Q12, Q14

\begin{abstract}
In the past years, farmers suicide in India has become a major problem and denotes a social ill that could lead to a national tragedy. This article seeks to explain the phenomenon of suicide among Indian farmers. The article focuses only on economic factors to explain suicides. We have constructed a theoretical model, based on the assumptions which show that over-indebtedness, price of inputs, and uncertainty of the return on the technology used by the farmers can cause suicide. Therefore, we assume that over-indebtedness has a negative impact on the livelihood of Indian farmers and on their capacity to repay the debt. Consequently, an assumption is made between suicide and the decrease of utility on one side and suicide and an increase in prices for inputs on the other side. Ultimately, suicide becomes a rational and optimal choice that improves well-being in the sense that farmers are relieved from all burdens of material life.
\end{abstract}

Keywords: farmers suicide, poverty, indebtedness, rational choice, GMO technology

\section{Introduction}

Theoretical works on the economics of suicide often assume that economic difficulties are the common risk factors for suicide. In literature, suicide is typically analyzed from the microeconomic perspective under the assumption that an individual commits suicide as a consequence of rational choice (Kimenyi \& Shughart II, 1986; Campaniello et al., 2012; Perry 
\& Hasisi, 2015). In psychiatric analysis the rational choice assumption of suicide is debatable (Pilpel \& Amsel, 2011; Ho, 2014, Michel et al., 2017). However, it is considered that individuals at a terminal life phase as a result of illness are capable to take the rational suicide decision (Lester \& Yang, 1996).

Yang (1987) has used cost-benefit analysis to study the phenomenon of suicide. Its modeling is analogous to the supply-demand model. Specifically, in this static model, the intersection between supply and demand curves determines the likelihood of an individual to commit a suicidal act. In addition, Huang (1997) has carried out a microeconomic modeling analysis of a suicide bid. Under such an approach, he undertook an original analogy between an individual wanting to commit suicide and a worker who wishes to withdraw from the labor market. If the worker decides to allocate zero hours for work, he will leave the labor market. Similarly, if the individual undertakes to allocate an amount equal to zero effort to stay alive, he will renounce the 'marketplace of life'.

In contrast to the two models developed above, the one developed by Hamermesh and Soss (1974) is dynamic and therefore takes into account the timing issues. These authors have formalised the problem of suicide through a model of maximising an inter-temporal utility function. In this model the utility function depends on individual consumption, which itself is a function of age and permanent income ${ }^{1}$.

Hamermesh and Soss (1974) also assume that the individual processes a discount rate which is considered for the entire period of his life. In order for suicide to become a choice that improves well-being ${ }^{2}$, the individual must reach the point where he will continue to live a negative expected utility. However, it is important to note that this does not necessarily mean that each future period is characterised by a negative net utility.

The writings defended by Hamermesh and Soss (1974) have found a theoretical extension. Thus, Koo and Cox (2008) have extended the analysis by substituting the permanent income hypothesis by the use of relative income. Relative income is assumed to be a function of human capital. In extenso this will also mean that the relative income of an unemployed person depreciates because the unemployed person loses the opportunity to develop their human capital through training whilst employed. The model shows how high unemployment may lead to an increase in suicide rates. The model of Hamermesh and Soss (1974) has also been empirically verified (Molina \& Duarte, 2006; Neumayer, 2003; Viren, 2005) to show a significant correlation between the economic cycle and the suicide rate.

Here we develop a model in which uncertainty in the productivity of the technology plays an important role in the decision of committing suicide. Our goal is to show the debate on the issue of farmers suicide in India.

Suicide is a very complex phenomenon associated with psychological, economic, cultural and social factors (Dongre \& Desmukh, 2012). All these factors can also be interrelated pushing individuals to commit suicide. However, we do not want to analyze the complex phenomenon of suicide itself. Instead, we only want to present by means of a theoretical model the economic causes of suicide among farmers in India. Indeed, according to Merriott (2017) suicide in India is associated with socio-economic factors rather than mental health problems.

For this reason indebtedness is considered as the main cause of suicide in India (Merriott, 2017; Kennedy \& King, 2014; Irengbam, 2012; Mishra, 2008) but in addition there are other factors which explain farmers suicide, such as the prices of farm produce, poor

\footnotetext{
${ }^{1}$ Permanent income is the income stream for perpetual wealth in the broadest sense of the economic agent.

${ }^{2} \mathrm{~A}$ farmer can put a negative value on his life so that suicide becomes the better option when there is zero value.
} 
irrigation, increased cost of cultivation, and access to informal credit markets (Dongre \& Desmukh, 2012).

According to Sarmistha (2002), small farmers may no longer borrow from banks because of over-indebtedness. In addition, financial institutions generally refuse to extend credit to the agricultural sector. Indeed, the State in India does not subsidise anymore on irrigation infrastructure. So to improve their yields, farmers are thus forced into debt to purchase water pumps. And thus, no longer able to rely on bank loans, farmers are financed on the informal credit markets (usually relational) such as moneylenders and pawnbrokers.

Hence given the excessive borrowing from moneylenders, input dealers have become the authoritative source of credit financing. Local lenders are expelled and replaced by lenders/traders from different ethnic groups and castes who like to lobby for aggressive or even violent means to recover their money. This threat and the shame of not being able to repay their debt then leads some farmers to suicide (Mishra, 2008). According to this author, those affected by suicide are mainly small farmers who have no alternative income to meet the risk of loss of crop.

According to Mishra (2014), there were 284,673 suicides of farmers in India over the period from 1995-2012, most of which came from cotton producing States.

"The states of Madhya Pradesh and Maharashtra with large cotton-growing areas and with relatively higher incidence of farmers' suicides, in contrast to the all India trend, show an increasing trend in recent years."(Mishra, 2014)

Indian States which were most heavily impacted are those who have adopted the culture of Genetically Modified Organisms (GMO), whereas the data from the Department of Indian National Crime highlight that over the period of 2010-2012 the three-year average suicide rate for male farmers (per 100,000 people) in the State of Maharashtra was 41.8, with Vidarbha considered as the epicentre of farmers suicide, but which is not the only area affected by the issue. In this region $95 \%$ of farmer suicide victims were heavily indebted. The suicide rate for farmers has also increased in recent years for Madhya Pradesh, a predominantly cotton growing state (after Maharashtra).

We assume that the economic factors in the world of consumerism where well-being and social position of households depend only on their economic success can explain the decision to commit suicide. In addition this paper links suicide with the technology used by the farmers but also to the prices of inputs and consumption goods. The technology variable can be replaced by any other factors which can explain suicide.

Indeed, Gruère and Sengupta (2012) show that there is a relationship between cost of production, technology, and farmers suicide. According to Rao and Dev (2009) the living standards of farmers using GMOs have improved. Farmers who grow transgenic cotton, mainly finance purchasing chemical fertilizers, pesticides, and seeds through borrowing. If the crop fails due to a lack of rain, or because of other factors that affects the plants, then the farmer is no longer in a position to meet loan installments, which, in turn, drives many of them to suicide. Consequently, the differences in yields between various farmers do not only come from their personal characteristics (education) and endogenous factors like the access of irrigation (Sadanandan, 2014), but can be attributed to the technology itself.

Thus, we develop a model that links suicide to economic factors. The model takes into consideration micro and small enterprises or farmers who do not have enough financial capital to sustain the economic development of their enterprises and who are more prone to commit suicide. The originality of our approach lies in the consideration of uncertainties in 
the technology adopted by the producers, and price changes (to reveal the suicide of farmers) of resources. These two factors are crucial variables in the analysis of farmers suicide in India.

In the situation described above, producers or farmers have an option to take on debts, with the non-expected adverse effect that when the individual is indebted suicide may become a rational alternative when the cost of living becomes unbearable (Dandekar \& Bhattacharya, 2017).

Thus, we show that suicide can be caused by four factors:

1. High-interest rates

2. Uncertainty related to the performance of the technology

3. Higher input prices

4. A loss of expected utility

To develop the suicide model samples of small farmers in India are taken into consideration.

Currently there is a debate on farmers suicide in India. Some authors relate farmers suicide to the technology adopted in GMO seeds by small farmers to improve their production (Jayaraman, 2004; Dandekar \& Bhattacharya, 2017).

For a discussion on the issue of farmers suicide and bio-technology see for instance Thomas and de Tavernier (2017). We must consider the fact that technology can have a negative effect on small farmers if technology is not well utilized. Hence, this study contributes to the existing economics of suicide literature in two ways:

i) The relationship between farmers suicides and increase of agricultural input prices is investigated by incorporating indebtedness

ii) Building a theoretical model which provides a background and clear understanding for future empirical research concerning farmers suicide in developing countries such India

Our paper is organized into five sections. In the second section, we argue that suicide is due to the high-interest rates and technological uncertainty. In the third section, we explain the suicide of producers through the decrease of their utility. Subsequently, in the fourth section, we remove the assumption of constant prices in order to highlight the impact of price changes on the usefulness of the producer. In the fifth and last section, we present our main conclusions.

\section{Theoretical model}

For the model we are looking at a simplification of an economy composed of a farmer who produces a quantity $\mathrm{Q}$ and consumes a good $\mathrm{C}$. We hereby recognize that this small farmer acquires inputs on credit knowing that he/she has also the ability to borrow on the formal credit market and the informal credit market. Therefore, the interest rate $r$ varies with the market price. It is also believed that the interest rate set on the informal market is greater than the interest rate on the formal market (Bottomley, 1963). For a study on the formation of the interest rate in the informal credit market see for instance Bhukuth et al., (2018).

Thus, in our model, the farmer suicide is explained by three arguments:

- the uncertainty regarding the yield advantage of technology (the technology can be for example the transgeniccotton seeds or any other technology)

- the indebtedness of the farmer

- the change in production costs and output prices which negatively affect the producer's welfare

We start by considering a farmer who chooses to adopt the new technology which we denote as S. This technology can theoretically increase the production of farmers and 
minimize the cost, for example, the cost of phytosanitary (insecticides, pesticides) used can be reduced if the new technology is adopted (GMO seeds). We assume that this new technology is risky and the farmer cannot accurately determine its performance.

"Such uncertainty will be represented by a random variable that follows a uniform distribution on the interval $[0,1]$. Thus, when $\theta=0$, the risk is zero and when $\theta=1$ uncertainty is high."

The expected result, noted $\tilde{y}$, depends on the amount of labour $L$ of the farmer, the quantity of insecticide $I$ and the new technology $S$.

We further assume that the farmer buys seeds and insecticides at successive prices $P_{s}$ and $P_{i}$ that are assumed to be exogenous. Insecticides are used by farmers to increase yields of seeds and make them more resistant to insects. So, the total cost is given by $C_{T}=\left(P_{i} I+P_{S} S\right)$.

The expected return can be written as follows:

$\tilde{y}=f(L, I)+E(\theta) g(S)$

We assume here that the functions $f$ and $g$ are twice continuously differentiable and concave on $I R$ with their arguments.

The farmer uses an amount of credit to purchase inputs ( $S$ and $I$ ), and we assume that $d$ is related to the amount of debt borrowed. Dis the total amount of debtthatthe farmer mustrepay backat the end of the season periodand $r$ isthe market interest rate. The total amount of debt $D$ that the farmer has to pay is:

$$
D=d(1+r)
$$

The amount borrowed is used to pay the costs of inputs resulting in:

$$
\begin{gathered}
\frac{D}{(1+r)}=P_{i} I+P_{S} S \text { and subsequently: } \\
D=d(1+r)=\left(P_{i} I+P_{S} S\right)(1+r)
\end{gathered}
$$

The farmer maximizes his expected profits given exogenous output price y $P_{y}$. Then the expected profit maximization equationcan be expressedas follows:

$$
\begin{aligned}
& E(\pi)=P_{y} \tilde{y}-\left(P_{i} I+P_{S} S\right)(1+r) \\
& \operatorname{Max}_{(L, S, r)} E(\pi)=P_{y} f(L, I)+P_{y} E(\theta) g(S)-\left(P_{i} I+P_{S} S\right)(1+r)
\end{aligned}
$$

The first order conditions for expected profit maximization are:

$$
\begin{aligned}
& \frac{\delta E(\pi)}{\delta L}=P_{y} f_{L}(L, I)=0 \\
& \frac{\delta E(\pi)}{\delta S}=P_{y} g^{\prime}(S) E(\theta)-P_{S}(1+r)=0 \\
& \frac{\delta E(\pi)}{\delta I}=P_{y} f_{I}(L, I)-P_{i}(1+r)=0
\end{aligned}
$$


Equations (7) and (8) together offer the following relationship:

$$
f_{I}(L, I)=\frac{P_{i}}{P_{S}} g^{\prime}(S) E(\theta)
$$

This relationship implies that the marginal productivity of insecticide increases with the adoption of the new technology, ceteris paribus. Thus, the new technology helps not only to reduce the insecticide usedbut also to increase its efficiency.

From equation (7) we are able to determine at what interest rate the farmer begins to invest, thus:

$$
r^{*}=\frac{P_{y}}{P_{S}} g^{\prime}\left(S^{*}\right) E(\theta)-1
$$

For the interest rate to become positive, it means that $g^{\prime}\left(S^{*}\right) E(\theta)>\frac{P_{S}}{P_{y}}$.

The interest rate depends on:

i) the average level of uncertainty,related with performance of the new technology the seed price

ii) the marginal productivity of the new technology, which isinversely proportional to

A positive interest rate implies that $g^{\prime}\left(S^{*}\right) E(\theta)>\frac{P_{S}}{P_{y}}$ where the value of the marginal product of technology exceeds the prices. follows:

From equation (3), we can determine the level of credit requested by the farmer as

$$
d^{*}=P_{i} I^{*}+P_{S} S^{*}
$$

The level of requested credit is a function of the equilibrium quantities of production factors. Since the interest rate is a positive function of the marginal product of new cotton seeds, if he wants to obtain a high credit level from the lender, the farmer will hide the reality and will pretend that the profitability of new technology is certain. In that case, if the farmer obtains a high amount of credit while $\theta$ is close to 1 , he will eventually be unable to repay his debt. Thus, the uncertainty about the performance of new technology together with the requested amount of credit could be the origin of indebtedness which then in turn becomes a major and proximate cause of farmer suicides in India.

\section{Decline of the farmer utility as a factor to suicide}

The Hamermesh and Soss (1974) economic theory of suicide was the first study to apply the utility maximization framework to suicide. In our model, we use their framework and we assume that in order for suicide to be an improvement of well-being that the individual commits suicide when the value of her/ his utility falls to or below a certain value $\underline{U}$ (the minimum utility for which suicide becomes an optimal choice).

We explain the decline in the use of utility from the farmer as being the cause of suicide. Therefore, the farmer must maximize his/her utility. We assume they consume only one good $C$.

Hence, its utility function $U$ is of the following form:

$$
U=U(C)
$$


We consider the following standard assumptions: $U^{\prime}>0$ and $U^{\prime \prime}<0$.

The farmer's income constraint can be written as follows:

$$
C=\tilde{y}-(1+r) d=f(L, I)+E(\theta) g(S)-(1+r) d
$$

The farmer maximizes his utility function subject to income constraint. Thus given the Lagrange multiplier $\lambda$, the program can be written as follows:

$$
\begin{aligned}
\operatorname{Max} \ell(.) & =U(C)+\lambda[\tilde{y}-(1+r) d-C] \\
\frac{\delta \ell(.)}{\delta C} & =U^{\prime}(C)-\lambda=0 \Rightarrow U^{\prime}(C)=\lambda \\
\frac{\delta \ell(.)}{\delta L} & =\lambda f_{L}(L, I)=0 \\
\frac{\delta \ell(.)}{\delta I} & =\lambda f_{I}(L, I)=0 \\
\frac{\delta \ell(.)}{\delta S} & =\lambda\left[E(\theta) g^{\prime}(S)-(1+r)\right]=0 \\
\frac{\delta \ell(.)}{\delta \lambda} & =f(L, I)+E(\theta) g(S)-(1+r) d-C=0
\end{aligned}
$$

From equation (17) we can write the interest rate equation as:

$$
(1+r)=E(\theta) g^{\prime}(S)
$$

And from equation (18), we can define the amount of good $C$ consumed by the farmer, we obtain:

$$
C=f(L, I)+E(\theta) g(S)-(1+r) d
$$

Then substituting (19) into (20), we find:

$$
\begin{aligned}
& C=f(L, I)+E(\theta) g(S)-E(\theta) g^{\prime}(S) d \\
& C=\tilde{y}-E(\theta) g^{\prime}(S) d
\end{aligned}
$$

Sic stantibus ceteris paribus the consumption of good $C$ depends on the productivity of the new technology and on the average level of risk associated with technology (or risk of change in the weather) and the level of debt.

For a $\theta=0$ (that is to say, in the absence of uncertainty), the consumption depends only on the crop yield. When the farmer reaches a point where to continue to live will bring him a negative utility, to improve his well-being, he will opt to commit suicide (Hamermesh and Soss, 1974).

We assume that $\underline{U}$ the minimum utility level below which the farmer chooses suicide is:

$$
\underline{U}=U(\underline{C})
$$


Given the monotonousness of preferences:

$$
U(\underline{C}) \leq 0 \Leftrightarrow \underline{C} \leq 0
$$

Therefore:

$$
\underline{C}=\tilde{y}-E(\theta) g^{\prime}(S) d \leq 0
$$

We replace $d$ by: $\frac{D}{(1+r)}$ we have:

$$
\underline{C}=\tilde{y}-E(\theta) g^{\prime}(S) \frac{D}{(1+r)} \leq 0
$$

The Indebtedness implies the decline in the consumption level, ceteris paribus. The consumption level $C$ becomes negative if $D \geq \frac{(1+r)}{E(\theta) g^{\prime}(S)} \tilde{y}$ (in other words, the ability to repay debt exceeds the farmer's total return).

If the yield of the technology decreases this will also imply the aggravation of the indebtedness state and therefore suicide to become a choice that improves the farmer's wellbeing.

Why do the debt levels decrease with the average level of risk?

In fact, we argue that risk-averse farmers would be more likely to not adopt the new technology. Analytically, to assess the impact uncertainty of expected yield, from the adoption of new technology, onthe marginal utility of farmers, we replace $\mathrm{C}$ in equation (13) and we have the following equation:

$$
\lambda=U^{\prime}\left[\tilde{\mathrm{y}}-\mathrm{E}(\theta) \mathrm{g}^{\prime}(\mathrm{S}) \mathrm{d}\right]
$$

The equation (27) states that if the degree of uncertainty is high that the marginal utility of consumption is low. In fact, if the farmer chooses the risky technology, the probability that he/she finds themselves in a situation of indebtedness increases. As a result, the utility level falls below a certain threshold $\underline{U}$.

At last, if the initial amount of credit increases, the marginal utilityof the farmerdecreases and he will be unable to satisfy his consumption good demand. The utility can also decrease when the prices of input increase.

\section{Price effects}

We have assumed in the last section that prices were exogenously fixed to unity. But, what are the impacts of variation in prices upon the Indian farmers behavior?

We now consider that the prices are endogenous (different to unity) and vary in relation to the market forces. We assumed that $P_{y}$ (the market price of output), $P_{i}$ (the market price of insecticides), $P_{s}$ (the price of the technology) and $P_{c}$ (the price of consumer good $C$ ) are all endogenous. 

follows:

Thus formally, the new maximisation function of the expected profit is given as

$$
\operatorname{Max}_{(L, S, r)} E(\pi)=P_{y}(f(L, I)+E(\theta) g(S))-\left(P_{i} I+P_{S} S\right)(1+r)
$$

The first order conditions maximizing the expected profit are:

$$
\begin{aligned}
& \frac{\delta E(\pi)}{\delta L}=P_{y} f_{L}(L, I)=0 \\
& \frac{\delta E(\pi)}{\delta S}=P_{y} g^{\prime}(S) E(\theta)-P_{S}(1+r)=0 \\
& \frac{\delta E(\pi)}{\delta I}=P_{y} f_{I}(L, I)-P_{I}(1+r)=0
\end{aligned}
$$

In order to better understand the impact of the variations in prices on farmers behavior from equation (30) and (31) we are able to extract two relations (32) and (33):

$$
\begin{aligned}
& \frac{P_{y}}{P_{S}}=\frac{(1+r)}{g^{\prime}(S) E(\theta)} \\
& \frac{P_{y}}{P_{I}}=\frac{(1+r)}{f_{I}(L, I)}
\end{aligned}
$$

Assuming that the interest rate set, the higher the marginal productivity of the technology the higher will be the demand for the new technology and the higher the level of price $P_{S}$. level of $P_{y}$.

Hence, this implies an increase in the quantity of output supplied and a decrease in the

By consequence the ratio $\frac{P_{y}}{P_{S}}$ decreases.

If the interest rate increases, it means that the demand for credits is decreasing and the rate of investment is diminishing, which does not favour the fast spreading of the new technology. Subsequently, when the price of the technology is lowered, the quantity of output supplied is reduced and its price $P_{y}$ is increased.

By consequence, the ratio $\frac{P_{y}}{P_{S}}$ increases. In contrast, if the interest rate diminishes there is an increase in the diffusion of the new technology, so that the quantity of output supplied will decrease and therefore its price $P_{y}$ is increased.

Moreover, the adoption of the new technology aims to diminish the use of pesticides (for example $B t$ seeds technology is resistant to American bollworm pest(Helicoverpaarmigera) and also to reduce the price $P_{I}$. This implies that the ratio $\frac{P_{y}}{P_{I}}$ increases.

If the average level of risk associated with the new technology increases, the rate of diffusion of the new technology $B t$ decreases and the price $P S$ is reduced. This implies that the 
quantity of output supplied is reduced and its price $P y$ is increased. Consequently, the ratio of price $\frac{P_{y}}{P_{S}}$ increases.

By subtracting (31) from (26) we have:

$$
\lambda=U^{\prime}\left[\tilde{\mathrm{y}}-\frac{\mathrm{P}_{\mathrm{S}}}{P_{y}}(1+\mathrm{r}) \mathrm{d}\right]
$$

If the ratio $\frac{\mathrm{P}_{\mathrm{S}}}{P_{y}}$ decreases, the marginal utility of the farmer increases. For a level of credit nil, the marginal utility reaches its maximum point and it depends on the expected income.

For example, the prices of cotton fluctuate over time and depend on the level of supply and demand, which is influenced by policies in different producing countries. The subsidies given to cotton producers (in the USA and in the European Union) have the effect of reducing the price of the product on the global market. The reduction of the international price of cotton has negative effects on Indian farmers utility (mainly small planters). The marginal utility of Indian farmers decreases and the level of utility may reach the threshold $\underline{U}$ below which is when suicide becomes a rational and optimal choice significantly improveing their well-being.

In other examples, the price of $B t$ seeds being high, farmers buy the seeds on the alternative market at a lower price but remains higher than the price of traditional seeds. The problem seems to be attributable to the motivation of farmers who want to increase their profit margins and who have resorted to alternative or informal markets. This trend appears to be verified in other countries as this is the case for instance in China and as well as Argentina (Qaim \& de Janvry, 2003).

Bennett et al. (2004) show that the yield of GMC is lowered because it is cultivated on small areas due to the cost of seeds and farmed on the soil of worst quality which cannot ensure higher productivity of plants. These scholars suggest that Indian producers failed to correctly apply the operating instructions of suppliers. Moreover, basing their hope on the resistance of GMC, they have reduced the use of insecticide in the first year of cultivation making the plants vulnerable. The following year they had to increase the number of insecticides, as well as the quantity and the duration of spraying. The guarantee of a long-term resistance to GMO crop is not assured as the resistance decreases with time leading producers to use ever more insecticides.

\section{Conclusion}

In this paper we question the relationship between new technology and an increase in farmer suicide. The use of informal credit market reflects the imperfection of the credit market (Braverman \& Guash, 1986). This imperfection, as well as the over-indebtedness, draw our attention to the insurance sector, where insuring against risk has similar preconditions of indebtedness and ultimately to over-indebtedness. This dramatic phenomenon is reflected in the facts.

Our analysis tends to consider that the market concentration of new technology leads to indebtedness especially among small and uneducated farmers who are unable to use technology efficiently. It seems that the credit concern is to access the credit at usurious rates. The usurious rates (credit is taken with moneylenders), in general, are higher than the market rate, and the debt service grows faster than the repayment capacity of the farmer households 
which leads the households to a situation of over-indebtedness (Bottomley, 1963; Krishna et al., 2003). According to these findings, it seems plausible to suggest that farmers would be more likely to commit suicide because their space of possibilities is reduced as the debt becomes unbearable.

According to our theoretical model, we believe that policy proposals would become efficient if they were oriented toward supplying farmers with the following spectrum of choices:

- liberalization of the seed markets (anti-trust laws)

- promotion and improvement of the credit system

- and creation of an efficient insurance program against the risk of crop loss.

\section{References}

Bennett R.M., Ismael Y., Kambhampati U., \& Morse, S. (2004). Economic Impact of Genetically Modified Cotton in India. AgBioForum, 7(3), 96-100. http://www.agbioforum.org/v7n3/v7n3a01-morse.htm

Bhukuth, A., Ballet, J., \& Radja, K. (2018). An Analysis of Social Proximity and Interest Rate in Rural India. Economics and Sociology, 11(1), 156-171.

Bottomley. (1963). The Premium for Risk as a Determinant of Interest Rate in Undeveloped Rural Areas. Quarterly Journal of Economics, 77(4), 637-647.

Braverman, A., \& Guasch, L.J. (1986). Rural Credit Markets and Institutions in Developing Countries: Lessons for Policy Analysis from Practice and Modern Theory.World Development, 14(10-11), 1253-1267.

Campaniello, N., Diasakos, T., \& Mastrobuoni, G. (2012). Rational Suicide: Evidence from Changes in Inmates Expected Sentence Length. Working Paper, Collegio Carlo Alberto, $\mathrm{N}^{\circ} 247$.

Dandekar, A., \& Bhattacharya, S. (2017). Lives in Debt: Narratives of Agrarian Distress and Farmer Suicides. Economics and Political Weekly, 52(21), 77-84.

Dongre, A.R., \& Desmukh, P.R. (2012). Farmers' Suicide in the Vidharba Region of Maharastra, India: A Qualitative Exploration of their Causes. Journal of Injury and Violence Research, 4(1), 2-6.

Gruère, G., \& Sengupta, D. (2011).Bt Cotton and Farmer Suicides in India: An EvidenceBased Assessment. Journal of Development Studies, 47(2), 316-337.

Hamermesh, D.S., \& Soss, N.M. (1974). An Economic Theory of Suicide. Journal of Political Economy, 82(1), 83-98, January/February.

Ho, A.O. (2014). Suicide: Rationality and Responsibility for Life. Canadian Psychiatry Journal, 59(3), 141-147.

Huang, W. (1997). A Life Force Participation Perspective of Suicide. 81-89, in: Lester, D. and Yang B. (eds.), The Economy of Suicide: Economic Perspective on Suicide. Commack, NY: Nova Science Publishers, 186 p.

Irengbam, D. (2012). Study of Suicide Victims of Agriculture in Punjab.International Journal of Management \& Business Studies, 2(1), 36-38, January/March.

Jayaraman, K.S. (2004). Illegal Seeds Overtake India's Cotton fields. Nature Biotechnology, 22(11), 1333-1334, November.

Kennedy, J., \& King, L. (2014). The Political Economy of Farmers' Suicide in India: Indebted Cash Crop Farmers with Marginal Landholdings Explain State-Level Variation in Suicide Rates. Globalization and Health, 10(1), 1-9.

Kimenyi, M.S., \& Shughart II, W.F. (1986). Economics of Suicide: Rational or Irrational Choice. Atlantic Economic Journal, 14(1), 120-121. 
Koo, J., \& Cox, W.M. (2008). An Economic Interpretation of Suicide Cycles in Japan. Contemporary Economic Policy, 26(1), 162-174.

Krishna, A., Kapila, M. Porwal, M., \& Singh, V. (2003). Falling into Poverty in a HighGrowth State. Economic and Political Weekly, 43(26).

Lester, D., \& Yang, B. (1996). An Approach for Examining the Rationality of Suicide. Psychological Report, 79, 405-406.

Merriott, D. (2017). Factors Associated with Farmer Suicide Crisis in India. Journal of Epidemiology and Global Health, 6(4), 217-227.

Michel, K., Valach, L., \& Gysin-Maillart, A. (2017). A Novel Therapy for People Who Attempt Suicide and Why We Need New Models of Suicide. International Journal of Environmental Research and Public Health, 14, 243, 1-15.

Mishra, S. (2008). Risks, Farmers' Suicides and Agrarian Crisis in India: Is There a Way Out?. Indian Journal of Agricultural Economics, 63(1), 38-54, on: http://www.igidr.ac.in/pdf/publication/WP-2007-014.pdf.

Mishra, S. (2014). Farmers' Suicides in India, 1995- 2012: Measurement and Interpretation. Asia Research Centre Working Paper 62, London School of Economics.

Molina, J.A., \& Duarte, R. (2006). Risk Determinants of Suicide Attempts Among Adolescents. American Journal of Economics and Sociology, 65(2), 407-434.

Morrell, S., Taylor, R., Quine, S., \& Kerr, C. (1993). Suicide and Unemployment in Australia 1907-1990. Social Science \& Medicine, 36(6), 749-756.

Neumayer, E. (2003). Are Socioeconomic Factors Valid Determinants of Suicide? Controlling for National Cultures of Suicide with Fixed-Effects Estimation. CrossCultural Research, 37(3), 307-329.

Perry, S., \& Hasisi, B. (2015). Rational Choice Rewards and the Jihadist Suicide Bomber. Terrorism and Political Violence, 27(1), 53-80.

Pilpel, A., \& Amsel, L. (2011). What is Wrong with Rational Suicide. Philosophia, 39, 111123.

Rao, N.C., \& Dev, S.M. (2009). Socio-Economic Impact of Transgenic Cotton. Agricultural Economics Research Review, 22, 461-470.

Qaim, M., \& De Janvry, A. (2003). Genetically Modified Crops, Corporate Pricing Strategies, and Farmers' Adoption: The Case of Bt Cotton in Argentina. American Journal of Agricultural Economics, 85(4), 814-828.

Sadanandan, A. (2014). Political Economy of Suicide: Financial Reforms, Credit Crunches and Farmers Suicide in India. Journal of Developing Areas, 48(4), 287-307.

Sarmistha, P. (2002). Household Sectoral Choice and Effective Demand for Rural Credit in India. Applied Economics, 34(14), 1743-1755.

Thomas, G., \& de Tavernier, J. (2017). Farmer-Suicide in India: Debating the Role of Biotechnology. Life Sciences, Society and Policy, 13(8), 2-21.

Yang, B. (1987). Is suicide a rational choice? An economic approach. Understanding and Preventing Suicide, 15-20.

Viren, M. (2005). Suicide and Business Cycles: New Empirical Evidence. Applied Economics Letters, 12(14), 887-891. 